\title{
Researching Entrepreneurships' Role in Sustainable Development
}

\section{INTRODUCTION}

Sustainable development is arguably the most significant issue of today. Each day, we hear accounts of ozone depletion, climate change, and the destruction of biodiversity as well as details about the detrimental and potentially lethal consequences these issues have for living species (e.g., IPCC, 2007; United Nations, 2004). Scholars have argued, however, that entrepreneurial action can help this dire situation by preserving ecosystems, neutralizing climate change, decreasing environmental degradation and deforestation, improving farming practices, providing more access to fresh water, and maintaining biodiversity (e.g., Cohen \& Winn, 2007; Dean \& McMullen, 2007). Furthermore, in developing countries in particular, such entrepreneurial actions can positively contribute to education, productivity, socioeconomic status, physical health, and self-reliance at both the individual and societal levels (e.g., Wheeler et al., 2005). Finally, while research has shown that entrepreneurial action creates economic gains for investors, entrepreneurs, and economies (e.g., Easterly, 2006), we need more sustainable entrepreneurship research investigating how entrepreneurial action can serve as a mechanism for preserving nature and ecosystems while also providing economic and non-economic gains for investors, entrepreneurs, and societies at large.

This chapter builds on Shepherd and Patzelt (2011).

(C) The Author(s) 2017

D.A. Shepherd, H. Patzelt, Trailblazing in Entrepreneurship,

DOI 10.1007/978-3-319-48701-4_5 
When a community of scholars comes together with a shared research interest characterized by an agreed-upon set of assumptions (e.g., aim, central focus, research methods, and relevant literature streams) (Busenitz et al., 2003, pp. 287-288; Ogbor, 2000; Summer et al., 1990), an academic field emerges. Because the field of entrepreneurship itself is still emerging, it is unsurprising that scholars have failed to clearly define the sub-field of sustainable entrepreneurship and outline its core assumptions. Thus, the purpose of this chapter is to provide some clarity in this area. The framework we outline in this chapter is not meant to be a fully developed, conclusive scope of sustainable entrepreneurship, but we hope it contributes to the stream's continued development.

By creating a more meta-theoretical (as opposed to a purely theoretical) framework, we hope to attract scholars from different theoretical perspectives to be a part of this scholarly community. While our ultimate goal is to combine sustainable development and entrepreneurship to come to some agreement regarding a boundary distinguishing sustainable entrepreneurship from other fields, we also want to encourage scholarly diversity within this boundary (Cannella \& Paetzold, 1994) as both aims are crucial for advancing the field. Consensus around a field's definition/ boundary conditions is the foundation of knowledge generation and accumulation (Kuhn, 1974; Pfeffer, 1993), and diversity within those bounds enables scholars to make comparisons across theories (Feyerabend, 1980) that inspire creative visions (Gould, 1981) as well as allow those visions to be appraised as part of the continual discourse in the marketplace of ideas (Cannella \& Paetzold, 1994). That is, a more transparent and precise definition of sustainable entrepreneurship will "set the scene" for a more diverse stream of theory-based research that-even with little (or no) overlap in dependent variables, independent variables, and theorywill at least have the chance to lead to knowledge accumulation because any study can be "located" within sustainable entrepreneurship (or not). For example, two separate studies may investigate different issues and be driven by distinct theoretical roots, but they can both contribute to the emergence of the field.

Our goal is to welcome numerous theoretical viewpoints to the sustainable entrepreneurship sub-field and embrace the significant variation in terminology, data, and methods instead of trying to focus on "the" definitive dependent and independent variables. While some scholars want to quickly come to agreement on these issues in new fields of study, it is our opinion that diversity within a broader framework is more beneficial-at 
least for the time being. Next, we lay the foundation for this broader sustainable entrepreneurship framework and then suggest some potential research avenues within it.

\section{A Definition of Sustainable Entrepreneurship}

The literature on sustainable development contributes to a broader discussion of sustainability by describing what is to be sustained-namely, nature, life-support systems, and community (for a review, see Parris \& Kates, 2003)—and what is to be developed-namely, individuals, the economy, and society (see Leiserowitz, Kates, \& Parris, 2006; National Research Council, 1999).

\section{What Is to Be Sustained in Sustainable Entrepreneurship?}

Sustaining nature. With intrinsic value above and beyond simply being a life-support system (see Muehlebach, 2001), nature encompasses all the phenomena of the physical world, including the earth, biodiversity, and ecosystems (Parris \& Kates, 2003). Indeed, if these resources are not maintained, the survival of many species on the earth, including humans, is endangered. The destruction of the ozone layer, for example, has led to increased exposure to ultraviolet irradiation and thus higher rates of skin cancer (Slaper, Velders, Daniel, de Gruijl, \& van der Leun, 1996). In contrast, research has shown that humans' health improves significantly with exposure to natural green places (Pretty, Hine, \& Peacock, 2006). If individuals, organizations, and nations are proactive in preserving the earth, biodiversity, and ecosystems, nature can be sustained. One pathway to fulfilling this goal is through sustainable entrepreneurship. However, more research is needed to investigate entrepreneurial action's role as a mechanism for sustaining nature.

Sustaining sources of life support. Referring to the environment as "a source of resources and services for the utilitarian life support of humankind" (Parris \& Kates, 2003, p. 560), sustaining life support involves preserving the environment, natural resources, and ecosystem services. In other words, life support for humans can be severely jeopardized if environmental systems are not sustained. For example, millions of deaths per year (particularly in third-world countries) are caused by the pollution of water with infectious agents, bacteria, and chemicals (Montgomery \& Elimelech, 2007). In addition, the over-exploitation of natural resources 
over the last few decades has had severe consequences on life support for humans. The over-exploitation of minerals from mining, for instance, has caused large portions of land to become uninhabitable (Swanson, 1996), and over-fishing has resulted in reduced fish stocks and less marine biodiversity (Sala \& Knowlton, 2006). Furthermore, declining ecosystem services directly impact human life support. For example, contamination has reduced the purification capacity of aquatic habitats, ultimately leading to a shortage of drinking water (Zedler \& Kercher, 2005), and soil erosion has led to diminished soil fertility, which in turn has led to reduced crop yields (Schröter et al., 2005). More research is needed to gain a deeper understanding of entrepreneurial action as a mechanism for sustaining life support.

Sustaining communities. A community is made up of an intricate web of relationships between a set of people who share similar values, norms, meanings, histories, and identities (Etzioni, 1996). Communities' distinctive characteristics (and thus what makes them contribute to members' identities) are their culture, groups, and places, and when these factors are threatened, the community at hand may be lost. In terms of culture, it has been argued that "human beings have a right to culture-not just any culture, but to their own" (Margalit \& Halbertal, 2004, p. 529). Being able to create and maintain cultures within larger societies enables humans to secure their personal identities, and the loss of a cultural identity can have significant negative impacts. For example, research has shown that the loss of cultural identity has led to increased alcoholism among American Indians (Spicer, 2001) and reduced physical health and life expectancy in Australian Aborigines (McDermott, O’Dea, Rowley, Knight, \& Burgess, 1998). In addition to culture, families and other groups are also a source of personal identity and are often argued to be the foundation of welldeveloped communities (Miller, 2001). Research has shown that when the family breaks down, the disruption weakens individual well-being (Forste \& Heaton, 2004). Finally, places are important to communities as they can represent important public symbols of culture and history (Borer, 2006), thus providing a sense of identity (Padua, 2007). Even though places are vital to communities, however, efforts to preserve places are not always effective. For example, tourism often threatens important community places, such as the Great Wall of China (du Cros, Bauer, Lo, \& Rui, 2005), and air pollution continues to have harmful consequences for many places, such as cultural heritage sites in Florence (Monforti, Bellasio, Bianconi, Clai, \& Zanini, 2004). 
Research on how entrepreneurial action can contribute to sustaining communities has already begun. For instance, Peredo and Chrisman (2006) introduced the notion of community-based enterprise, describing how all individuals in a community can act as entrepreneurs. Because a community-based enterprise is "typically rooted in community culture, natural and social capital are integral and inseparable from economic considerations" (Peredo \& Chrisman, 2006, p. 309), suggesting that in poorer regions of the world, communities' members acting as entrepreneurs can lessen poverty while preserving the natural environment. As another example, (O’Neill, Hershauer, \& Golden, 2009) explained how the Navajo Nation, the largest Native American tribe in the USA, created an entrepreneurial venture (Navajo FlexCrete) that develops ecofriendly building supplies by recycling waste material. This venture not only builds economic, social, environmental, and cultural value for the Navajo Nation, but it also contributes to maintaining the native Navajo tribe's heritage. Future sustainable entrepreneurship research can add to the current body of knowledge by deepening our understanding of the entrepreneurial mechanisms for sustaining communities.

\section{What Is to Be Developed in Sustainable Entrepreneurship?}

Generating economic gains is a central tenet of entrepreneurship (Venkataraman, 1997) and is thus also part of sustainable entrepreneurship. However, the literature on sustainable development argues that in addition to economic gains, non-economic outcomes (i.e., benefits to people and society) are also essential in development goals (National Research Council, 1999). Depending on their own characteristics and goals, individuals and organizations are likely to prioritize economic and non-economic gains in different ways. Some sustainable entrepreneurs, for instance, may believe it is sufficient to merely ensure their organization's financial viability, whereas others may want to earn economic profit for themselves.

Developing economic gain. An economics viewpoint focuses on the generation of economic gains for the actor and/or society, which also serve as an important development goal. For instance, economic gains can improve individuals' socioeconomic status (Oakes \& Rossi, 2003) as well as result in enhanced emotional (Gallo \& Matthews, 2003), psychological (Twenge \& Campbell, 2002), and physical health (Hanson \& Chen, 2007). These effects of economic gains go beyond generational 
boundaries because parents' increased socioeconomic status often leads to improved childhood well-being and enhanced socioeconomic status for their children when they become adults (Conger \& Donnellan, 2007). In addition, individuals' subjective well-being (Diener et al., 1995) and physical health (Knowles \& Owen, 1995) tend to increase with economic development in the countries in which they live. Individuals are likely to readily accept the development of these economic gains as an outcome of entrepreneurship. Therefore, when we combine these gains with a construct of what is to be sustained, the result is likely to be accepted as sustainable entrepreneurship.

Developing non-economic gains for individuals. In addition to the economic gains that can result from sustainable entrepreneurship, there are many non-economic gains, including increased child survival, life expectancy, education, equity, and equal opportunity (Board Sustainable Development, 1999; Parris \& Kates, 2003). For example, in poor countries, one out of every ten children dies before the age of five (Millennium goals, United Nations), the primary causes of which are pneumonia, diarrhea, malaria, measles, and AIDS (www.childinfo.org). The main question of stakeholder research, for instance, appears to be "for whose benefit and at whose expense should the firm be managed?" (Freeman, 1994, p. 67). Past research has emphasized ways to ensure the gains generated by a business are distributed equitably between a firm and its stakeholders. When resources are not distributed fairly, the firm is exploiting its stakeholders.

Research in the budding field of social entrepreneurship and in the area of corporate social responsibility has argued that entrepreneurs can contribute significantly to providing non-economic gains to individuals. For example, Nobel Laureate Muhammad Yunus learned that impoverished people in Bangladesh were being exploited by loan providers who were charging more than $100 \%$ interest. These individuals had no choice but to accept these rates because they needed money to buy bamboo for the stools they built and sold to earn their living, and no one else provided loans. To help these individuals, Yunus founded Grameen Bank, a social enterprise aimed at offering the poor cheaper loans, which in turn enabled them to markedly improve their living situations (Yunus, 2005). Similarly, Victoria Hale, a social entrepreneur and former biopharmaceutical research scientist, founded OneWorld Health to provide people in low-income countries with medical treatment that would be unaffordable to them otherwise (Seelos \& Mair, 2005). Innovative and entrepreneurial corporate social responsibility activities can also provide significant ben- 
efits to individuals. For example, McDonald's Ronald McDonald House Charities (McWilliams \& Siegel, 2001) enables seriously ill children to stay with their parents when receiving medical treatment far from home. Future sustainable entrepreneurship research can contribute to our understanding of the entrepreneurial mechanisms for developing non-economic gains for individuals.

Developing non-economic gains for society. Gains to society include benefits for people living in that society; however, they are different from individual gains in that the latter may only go to a select few individuals whereas societal gains are accessible to all (or the vast majority of) societal members. For example, societies realize gains by developing the "well-being and security of national states, regions and institutions and, more recently, the valued social ties and community organizations" (Board of Sustainable Development, 1999, p. 25). The well-being of nations and regions encompasses inhabitants' satisfaction with life and happiness (Diener et al., 1995; Vemuri \& Costanza, 2006), and security refers to defense against both outside threats (e.g., by other nations [e.g., Steinbruner, 1978]) and inside threats (e.g., through economic [Parkhe, 1992] or environmental [Porter, 1995] decay). Societies can also realize gains by developing social ties and inter-personal relationships between societal members. In poorer regions with decreased human well-being, weak social norms, low inter-personal trust, corruption, and violence tend to proliferate (Narayan \& Petesch, 2002), representing significant impediments to societal development (Easterly, 2006).

Social entrepreneurship and corporate social responsibility studies have emphasized the importance of entrepreneurs in creating non-economic gains for society. For instance, Ibrahim Abouleish, a social entrepreneur, founded Sekem, an initiative that began by growing organic herbs for medicinal use in poor areas of Egypt. Not only did this initiative create jobs for locals, but it also improved the area's social structure and enhanced inhabitants' trust in society, thereby enabling people to escape poverty and regain control in their lives. By applying organic agriculture techniques, Sekem also helped preserve parts of the region's natural environment (Seelos \& Mair, 2005). As Burton and Goldsby (2009) argued, entrepreneurs and small business owners are often driven less by profit than shareholders of larger publicly held organizations, thus enabling them to act in more socially responsible ways. For example, one way entrepreneurs can contribute to the development of their local society is by keeping employment locally instead of shifting their operations to less 
expensive production sites. By explaining these issues in more detail, sustainable entrepreneurship research can deepen our understanding of how, why, and under what circumstances entrepreneurial action can generate gains for society.

\section{What Is Sustainable Entrepreneurship?}

A definition of sustainable entrepreneurship. So far in this chapter, we have outlined the constructs to be developed and constructs to be sustained. Now, we explain how the two are linked by entrepreneurial action, a topic informed by the entrepreneurship literature. According to Venkataraman (1997, p. 120), entrepreneurship as a scholarly field "seeks to understand how opportunities to bring into existence future goods and services are discovered, created and exploited, by whom and with what consequences." We offer the following definition for sustainable entrepreneurship, which builds on the shared affinity of a community of scholars interested in this topic and is informed by the sustainable development and entrepreneurship literatures:

Sustainable entrepreneurship is focused on the preservation of nature, life support, and community in the pursuit of perceived opportunities to bring into existence future products, processes, and services for gain, where gain is broadly construed to include economic and non-economic gains to individuals, the economy, and society. (Shepherd \& Patzelt, 2011, p. 137)

What sustainable entrepreneurship is not. If a definition tries to include everything, then it will end up representing nothing. Thus, in this section, we focus on research that-while likely very valuable-does not fit within the scope of sustainable entrepreneurship that we propose, thus delineating the boundaries of this sub-field. First, research that solely focuses on what is to be sustained without concurrently investigating what is to be developed does not qualify as sustainable entrepreneurship research. For example, sustainability-focused research, such as a study on climate change documenting a significant change in global temperatures over the last decade, is inarguably important; however, because it does not also consider the development of people, the economy, and/or society, it cannot be classified as sustainable entrepreneurship research. Second, research that solely focuses on development without concurrently investigating what is being sustained is not considered sustainable entrepreneurship research. 
For example, research investigating child survival resulting from the creation of a new antibody for inoculation is very important but is not considered sustainable entrepreneurship research because it does not take into account sustainability. Third, research that concurrently addresses what is being sustained and what is being developed but does not connect the two with discussions related to the identification, creation, or exploitation of future goods, processes, or services is not sustainable entrepreneurship research (but may be considered sustainable development research). For example, government-funded programs and non-profit organizations may improve the sustainability of biodiversity while simultaneously developing people through education; however, this work is often done through actions that are not necessarily entrepreneurial in nature. Again, while exploring these topics is valuable research, it is not sustainable entrepreneurship. Finally, entrepreneurship research focusing entirely on the economic outcomes of entrepreneurial action (i.e., individuals, firms, and/or society) without simultaneous consideration of sustainability outcomes is not sustainable entrepreneurship research.

Sustainable entrepreneurship and related concepts. While we just outlined several research streams that are not a part of sustainable entrepreneurship, there are several research streams the field overlaps with and/or includes. First, our characterization of sustainable entrepreneurship encompasses studies on ecopreneurship (i.e., environmental entrepreneurship), a field exploring the ways entrepreneurial action can help preserve the natural environment, including the earth, biodiversity, and ecosystems (e.g., see Schaper, 2005; Pastakia, 1998). With this goal in mind, ecopreneurship is part of sustainable entrepreneurship, but the two are not identical because ecopreneurship does not overtly explore, for instance, sustaining communities or the creation of non-economic gains for individuals and societies. Second, our conceptualization of sustainable entrepreneurship intersects with the notion of social entrepreneurship, which "encompasses the activities and processes undertaken to discover, define, and exploit opportunities in order to enhance social wealth by creating new ventures or managing existing organizations in an innovative manner" (Zahra, Gedajlovic, Neubaum, \& Shulman, 2009). While social entrepreneurship research explores the generation of (non-economic) gains for individuals and societies, it does not include preserving nature, sources of life support, or community. Finally, our definition of sustainable entrepreneurship embraces aspects of corporate social responsibility, which refers to firm actions that seem to promote some form of 
social good beyond firm interests and legal requirements (McWilliams \& Siegel, 2001). However, corporate social responsibility does not necessarily involve entrepreneurial action or innovation; rather, it often involves organizations' societal engagements (e.g., funding a sports team or donating to social organizations).

The clearer definition of sustainable entrepreneurship that we developed serves as a foundation for investigating where and how future research can contribute to the field's development. Within the meta-theoretic framework this definition affords, we can start to uncover how entrepreneurial action can connect sustainability and development at both the individual and community levels-a topic to which we now turn.

\section{Entrepreneurial Action Linking Sustainability and Development at the Individual LeVel}

Individuals' prior knowledge of the natural and communal environment is likely to be very important in terms of identifying potential opportunities that preserve the natural/communal environment and generate gains. For example, using their prior knowledge of aquatic chemistry and biology, individuals have uncovered opportunities to apply waste water treatment that decontaminates sewerage (Sonune \& Ghate, 2004). Individuals with little or no knowledge about environmental issues (e.g., about ozone layer chemistry, pollution, mining techniques, and aquatic chemistry) or about cultures and places may not even recognize that changes occur in these areas and that such changes directly influence human life. As a result, individuals like these are unlikely to recognize opportunities for action to maintain the natural and communal environment.

Prior entrepreneurial knowledge also plays a role in one's ability to identify third-person opportunities. Shane (2000) outlined three types of entrepreneurial knowledge that influence individuals' ability to recognize opportunities: prior knowledge of markets, prior knowledge of ways to serve markets, and prior knowledge of customer problems. First, prior knowledge of markets impacts the entrepreneur's decision of which market to enter. For example, when an individual has prior knowledge of customers and suppliers in a particular market, he or she is better able to evaluate whether a new technology will be successful in that market and what potential gains may result (Roberts, 1991). Based on this evaluation, the individual is able to determine whether an opportunity for market 
entry exists. Second, prior knowledge of how to serve markets helps in the identification of opportunities because it enables entrepreneurs to evaluate (and perhaps attain) the skills needed for market entry (von Hippel, 1988). Finally, prior knowledge about customer problems with existing products or services can help individuals recognize opportunities to introduce new offerings that address customers' pain points and are thus accepted by the market (von Hippel, 1988).

Together with previous knowledge, motivation plays a significant role in individuals' ability to identify potential sustainable development opportunities (McMullen \& Shepherd, 2006). Motivation likely points people and organizations toward signals of potential opportunities to preserve the natural and communal environment when they sense that their physical and psychological well-being is being threatened. These feelings trigger emotions, which in turn capture and direct attention to the problem at hand and instill the need to act. We explore some of these triggers.

First, individuals are often motivated to act on sustainable opportunities that enhance or uphold their own physical health. The decline of natural environment through pollution, for example, endangers many people's lives (Montgomery \& Elimelech, 2007), and the over-exploitation of natural resources reduces humans' life support by decreasing food availability (Sala \& Knowlton, 2006). In turn, these perceptions of threat and loss can lead to negative emotional reactions (Meijnders, Midden, \& Wilke, 2001), which likely motivate individuals to act on opportunities that decrease pollution, improve natural resource-exploitation practices, decrease oppression of ethnic/cultural groups, and so on.

Second, it appears that when the natural and communal environment declines, individuals' psychological well-being can be negatively affected as well. As one example, research has shown that declining natural and communal environments can diminish individuals' needs for relatednessnamely, their desire to connect with other people (Ryan \& Deci, 2000). For instance, declining communal environments can destroy important social relationships, such as ties between parents and children when families are dissolved. The dissatisfaction that results from psychological needs like these not being met or their fulfillment being thwarted can lead to intense negative emotions, such as fear, anger, frustration, loneliness, depression, and shame (Ryan \& Deci, 2000; Wei, Shaffer, Young, \& Zakalik, 2005), which then serve as an irritant that motivates action to remove its source (Foo, Uy, \& Baron, 2009). 
Therefore, the more individuals' physical and psychological health are endangered, the stronger their motivation will be to act on potential sustainable development opportunities to overcome these threats. That is, these types of threats (and potential opportunities) are more likely to lead to negative emotions that prompt the search for a solution (Mathews \& MacLeod, 1994). After recognizing the threat and overcoming their primary fear response, motivated individuals methodically pursue opportunities to escape or overcome this threat (Beck \& Clark, 1997). During this "elaborative strategic processing of [the] threat," individuals manage information slowly in an effortful and schema-driven way, but then a "secondary appraisal process occurs in which anxious individuals evaluate the availability and effectiveness of their coping resources to deal with the perceived threat" (Beck \& Clark, 1997, p. 53). This discussion leads to several interesting questions: How do individuals whose physical and psychological health is threatened by the decline of the natural or communal environment evaluate opportunities to escape that threat? To what extent do these threatened individuals use information (i.e., knowledge) about the natural/communal environment and their entrepreneurial knowledge to create or recognize potential sustainable entrepreneurship opportunities?

In addition to the negative emotions arising from feelings of personal threat, altruism can also result in emotions that direct attention to potential sustainable development opportunities. This altruistic motivation occurs when people empathize with or sympathize for underprivileged others (Batson, 1991; Davis, 1996). Empathetic individuals are able to take the perspective of disadvantaged others and personally experience similar emotions to those in need (Eisenberg, 2000). For example, people who empathize with individuals in poverty-stricken societies are able to experience (at least partially) their disadvantaged counterparts' burdens in providing for their children. The higher individuals' empathy is for others, the more motivated they become to identify and act upon potential opportunities that counter these others' negative emotional experiences and sorrows because these feelings are partly their own. That is, highly empathetic individuals are driven to pursue sustainable development opportunities that transform disadvantaged people's situation because by doing so, they can also improve their own emotional state.

In contrast to those who are more empathetic, sympathetic individuals are able to think and feel themselves into disadvantaged others' position, but they have different emotions than those actually going through the 
experience at hand (Eisenberg, 2000). Individuals who sympathize with very impoverished people, for example, are able to understand these individuals' distress regarding their children's nutrition and health, yet they will not personally experience these sorrows; instead, they will pity them on account of the burdens they face. As an altruistic emotion, pity motivates individuals to ease others' suffering even when giving aid may lead to substantial personal costs (Dijker, 2001). That is, individuals who are sympathetic to the poor will be driven to assist them and act upon entrepreneurial opportunities that improve their situation.

Empathy and sympathy lead to different levels of motivation to act upon potential opportunities that help people and society depending on the amount of personal distress the individual feels. Empathetic or sympathetic over-arousal can lead to more severe forms of personal distress (Hoffman, 1982) that cause highly negative emotional states that compromise individuals' psychological well-being (Eisenberg, 2000). To avoid these feelings of distress, individuals may become less altruistic and focus more on themselves (e.g., Wood, Saltzberg, \& Goldsamt, 1990), thus becoming less motivated to identify and act upon entrepreneurial opportunities that help others. However, individuals who are better at regulating their emotions and dealing with personal distress are more likely to avoid becoming overly distressed when empathizing with/sympathizing for disadvantaged others (Eisenberg, 1994; Eisenberg et al., 1998). Because these individuals' psychological and emotional well-being is threatened less from experiencing empathy and sympathy, they are likely to be more motivated to identify and act upon potential opportunities to develop society and help others with their problems.

\section{Future Research}

In Fig. 5.1, we offer a sketch of the role of entrepreneurial action linking sustainable and development outcomes as a basis for guiding future research. Entrepreneurial action provides a link between sustainable outcomes - those that preserve nature, sources of life support, and/or communities - and development outcomes - those that provide (financial or non-financial) gain to the entrepreneur and/or others. Entrepreneurial action arises from the formation of (third- and first-person) opportunity beliefs, which are influenced by knowledge, motivation, and perceptions of threat. Both knowledge (of the natural and communal environment) and prosocial motivation can influence individuals' ability to notice threats 


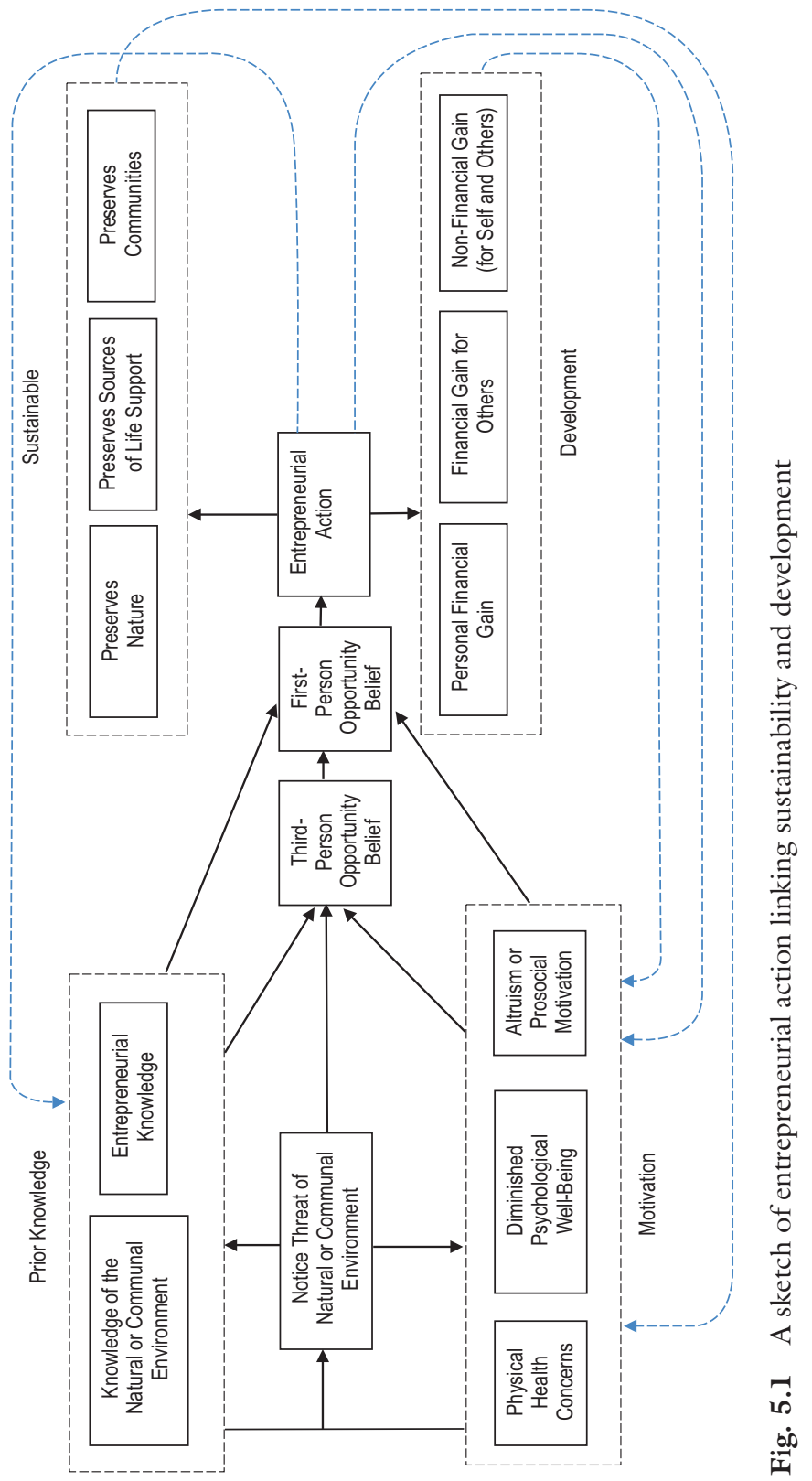


to sustainability, and in turn, this ability to notice threats can generate new knowledge and influence motivation. Prime motivators include physical health concerns, diminished psychological well-being, and altruism or prosocial motivations. Entrepreneurial action can subsequently influence both knowledge and management, which in turn influence the appraisal of threat. Similarly, development and sustainability outcomes can influence motivation.

\section{Entrepreneurial Action Linking Sustainability and Development at the Community Level}

Facilitating the transfer of research-based knowledge is one of the key steps toward sustainable development. The report of the World Summit for Sustainable Development held in Johannesburg in 2002 described “knowledge transfer to developing countries' as a key component of poverty eradication and frequently cites the importance of technology transfer for sustainable development" (Van Kerkhoof \& Lebel, 2006, p. 451). Several approaches have already been attempted to foster this transfer process. For example, transfer may be aided by efforts to translate knowledge in the form of jargon-laden science into terms that can be understood by the laypeople (Rogers, 1995). Moreover, providing incentives for universities can enhance their patenting rate in certain scientific fields, which is a pre-requisite to making tacit knowledge explicit and legally transferring it to users of the private sector (Shane, 2004). The literature also describes measures specific to facilitating knowledge transfer in sustainable development. For example, effective coordination between private companies and public institutions, including universities and research institutes, contributed to the successful commercialization of wind turbine technology (Lewis \& Wiser, 2007), and public-private partnerships between universities and firms have been described as an effective means to commercialize basic knowledge in the solar-energy sector (Mallett, 2007).

Although the above examples demonstrate that the transfer of researchbased knowledge from the scientific community to the user community can be actively promoted, the effectiveness of this process in generating sustainable development-namely, sustainable development actions by users - appears to be limited. For example, Roux, Rogers, Biggs, Ashton, and Sergeant (2006) stated that there is misunderstanding and friction between researchers and practitioners; that is, there are fundamentally dif- 
ferent operational working philosophies and operational cultures between the community that generates the knowledge and the community that uses it (Havens \& Aumen, 2000). Van Kerkhoof and Lebel (2006, p. 451) concluded, "It is somewhat ironic that despite widespread evidence of the failure of transfer and translation models to achieve sustainability-oriented outcomes in agriculture, health, and other sectors, they still hold appeal in the imaginations of researchers and policy makers."

Although science has the potential of offering solutions to sustainable development issues, if its research-based knowledge remains unconnected to the "real world," then it remains a purely academic endeavor with little social relevance (Welp, de la Vega-Leinert, Stoll-Kleemann, \& Jaeger, 2006, p. 170). A mechanism is required to make this connection (Ribot, 2006), and it must do so in a context characterized as "messy" (Kasperson, 2006). Entrepreneurial action represents a mechanism that operates in contexts of high uncertainty (Knight, 1921) and may serve to connect scientific and user communities. In this way, research-based knowledge may reveal potential entrepreneurial opportunities for sustainable development. In this section, we focus on entrepreneurial action as a mechanism that facilitates the transfer of research-based knowledge into users' sustainability behaviors and as a mechanism that facilitates feedback from users to scientists in the generation of further research that can impact the sustainability of development.

Although there may be a "race" to commercialize a sustainable development technology, research-based knowledge is unlikely to detail a fully formed version of such a technology. It is better thought of as a technology stimulus that triggers entrepreneurs to develop products, services, and/or processes that are eventually offered to the market. Given that researchbased knowledge of sustainable development often represents a technology stimulus rather than a fully developed and packaged opportunity, it is not surprising that the success of technology-transfer efforts to end users is mixed (at best). Indeed, an implicit assumption of "trickle down" explanations of research-based knowledge is that this explanation assumes an objective truth that scientists pass on to users, who in turn either adopt or reject the technology (Thompson \& Scoones, 1994). Information is assumed to "flow" one way-from scientist to users. However, users may be the originators of either technical knowledge or improved practice (Thompson \& Scoones, 1994) that could inform scientific research on sustainable development (Lemos \& Morehouse, 2005). For example, the formation of communities including both scientists and users facili- 
tates their mutual communication and understanding and can facilitate the development of a sustainable natural resource-management strategy (Ewing, Grayson, \& Argent, 2000), and feedback from users to scientists has been found to enhance the credibility, legitimacy, and relevance of scientific knowledge on air pollution (Tuinstra, Hordijk, \& Kroeze, 2006). With respect to renewable energy technologies, close user involvement in the design and planning process of solar collectors and biomass heating systems has been found to yield improved and widely disseminated technologies (Ornetzeder \& Rohracher, 2006).

Although the above examples illustrate that feedback from users to the scientific community may indeed be a critical component of the sustainable development process, it appears that effective feedback is difficult to achieve because fundamental differences exist in working philosophies and operational cultures between scientific and user communities. For example, Roux et al. (2006) reported that users view scientists as having an inward-looking and self-serving culture, having little regard for application contexts, and being incapable of contributing to the value-based debate that usually governs problem solving in the real world. On the other hand, scientists consider practitioners as being more interested in pursuing their own rather than the ecosystem's interests, having a poor understanding of scientific processes, and not being able to articulate their needs effectively. In line with these arguments, various studies have illustrated the obstacles of efficient communication between user and scientific communities in the context of sustainable development (Havens \& Aumen, 2000).

Perhaps entrepreneurial actions can serve as an important link between scientific and user communities to facilitate these feedforward and feedback processes and thus impact the generation and adoption of sustainable development products and/or services.

\section{Scientists Who Become Entrepreneurs}

Particularly in technology-based industries, entrepreneurs are often scientists who have left academia in order to exploit technological opportunities developed at university or public research institutes (Zucker, Darby, \& Brewer, 1998). These entrepreneurs are able to "speak the language" of both the academic researchers from whom they acquire new technologies and the users of these technologies who are their customers. Entrepreneurs can receive direct verbal feedback from users about potential improvements and future development paths for their sustain- 
able technologies (Ornetzeder \& Rohracher, 2006), or they can receive indirect feedback by the market indicating which technologies users desire and which they do not. Both types of feedback can be passed on to the scientific community to suggest and motivate areas of research that reflect users' needs. These arguments are consistent with research indicating that the inclusion of individuals external to the scientific and user communities can facilitate the communication and transfer of knowledge on sustainable development (Bruckmeier, 2005). Entrepreneurs are likely very able and motivated to perform this role, but there is likely considerable heterogeneity in this motivation. We need to gain a deeper understanding of how entrepreneurs effectively link scientific and user communities to develop and refine sustainable development opportunities as well as gain insights into why some entrepreneurs are more motivated to provide this link and communicate with both communities, whereas others are reluctant to do so at all or prefer to communicate with only one community.

\section{Entrepreneurial Action Generates Feedback}

In addition to serving as an information pathway, entrepreneurial action may also represent a signaling mechanism for the scientific community by indicating which research-based knowledge users accept and which they do not. Specifically, there is high variance in the performance of entrepreneurial firms, particularly in technology-based industries, for which the failure rates of new ventures are high (Bruno, McQuarrie, \& Torgrimson, 1992). The success and failure of entrepreneurial ventures may indicate to the scientific community which type of research-based knowledge the user community values most and which type of research-based knowledge users are less likely to accept and adopt. For example, Jacobsson and Bergek (2004) found that successful firm entries in the wind- and solar-energy sectors have spurred the creation of new knowledge for these technologies.

Besides influencing the types of research-based knowledge created by scientists, entrepreneurs' pursuit of potential sustainable opportunities may also influence the amount of knowledge scientists create. Specifically, the results of sustainable entrepreneurial action can provide data and stimulus for the generation of new knowledge. For example, perhaps a technology developed by an entrepreneurial venture works but does so for an unexpected scientific reason. In attempting to understand why the technology works, scientific research may generate new research-based knowledge of sustainable development. To what extent does entrepreneurs' 
success in exploiting sustainable opportunities have on scientists' social, cultural, and/or organizational environments that motivates them to further advance research in that area of sustainable development? Perhaps, as Jobert, Laborgne, and Mimler (2007) reported, the success of entrepreneurial firms in the wind-energy sector and the population's participation in this success (e.g., by offering partial ownership of the technologies) changed social attitudes toward the technology in a favorable way, which motivated scientists to intensify their research in this area.

\section{Entrepreneurs as Translators}

Entrepreneurship scholars have the chance to complement existing studies on science-based stakeholder dialogues. This literature has identified that there is insufficient interaction between scientists and users and that this is caused by differences between the two communities in terms of the way each frames environmental problems and perceives risk. To overcome these obstacles and induce action by users, studies on science-based stakeholder dialogue have highlighted the importance of communicationbased methods, such as interviews, written reviews, workshops, interdisciplinary team work, and surveys (e.g., Lemos \& Morehouse, 2005; Welp et al., 2006). Although these studies are important for understanding how communication between scientific and user communities can facilitate sustainability, there is an implicit assumption that better understanding of research-based knowledge by users will enhance the likelihood of user action. While this may be true in some cases, it appears that when finding solutions to sustainability problems via the market mechanism, both scientists and users often do not have the necessary motivation and knowledge for action. Specifically, they likely do not possess sufficient knowledge about market structures, economic environments, and the discovery and exploitation of opportunities and may not be motivated to act in the highly uncertain context associated with exploiting sustainability opportunities. The entrepreneurial community does possess knowledge of market specificities, the best ways to serve markets, and customer (user) problems (Shane, 2000). Moreover, entrepreneurs have the motivation to act based on this knowledge even if the outcomes of these actions are highly uncertain (Knight, 1921; McMullen \& Shepherd, 2006). Thus, both communication and entrepreneurial action appear to be complementary mechanisms connecting scientific and user communities in order to achieve sustainability. Future research can explore how these mechanisms might be used together to enhance sustainable development. 
In sum, achieving sustainable development is highly dependent upon the effective transfer of research-based knowledge to the user community. This process is difficult, and a variety of measures have been suggested to make it more effective; however, these efforts have often been met with limited success (Van Kerkhoof \& Lebel, 2006). Perhaps entrepreneurial action can help bridge the scientific and user communities and facilitate knowledge transfer. What are the factors that enable entrepreneurial action to better transfer research-based knowledge to users and to communicate feedback from users to the scientific community? This entrepreneurial action-based feedback loop may become self-sustaining or self-enhancing - that is, the more positive feedback the scientific community receives from users, the better the created research-based knowledge will fit the needs of the user community. In turn, this will trigger users' feedback and so on.

\section{Future Research}

In Fig. 5.2, we offer a sketch of the role of entrepreneurial action in linking scientific and user communities as a basis for guiding future sustainable entrepreneurship research at the community level. The scientific community and the user community face obstacles to effective communication. The scientific community-based on its members' knowledge and motivation-generates research-based knowledge of sustainability, which the community of entrepreneurs can translate (based on their scientific and entrepreneurial knowledge) into a potential sustainable development opportunity. This potential opportunity is tested with potential users who provide feedback, and the potential opportunity is refined, which provides feedback to the scientific community, thereby influencing the form, amount, and motivation of specific types of sustainability research. The new research-based knowledge further influences the community of entrepreneurs and their conception of the potential sustainable development opportunity.

\section{Discussion And Conclusion}

In this chapter, our purpose was to offer a greater understanding of what constitutes the academic field of sustainable entrepreneurship and to offer some suggestions for moving it forward. We offered the following definition: sustainable entrepreneurship is focused on the preservation of nature, 


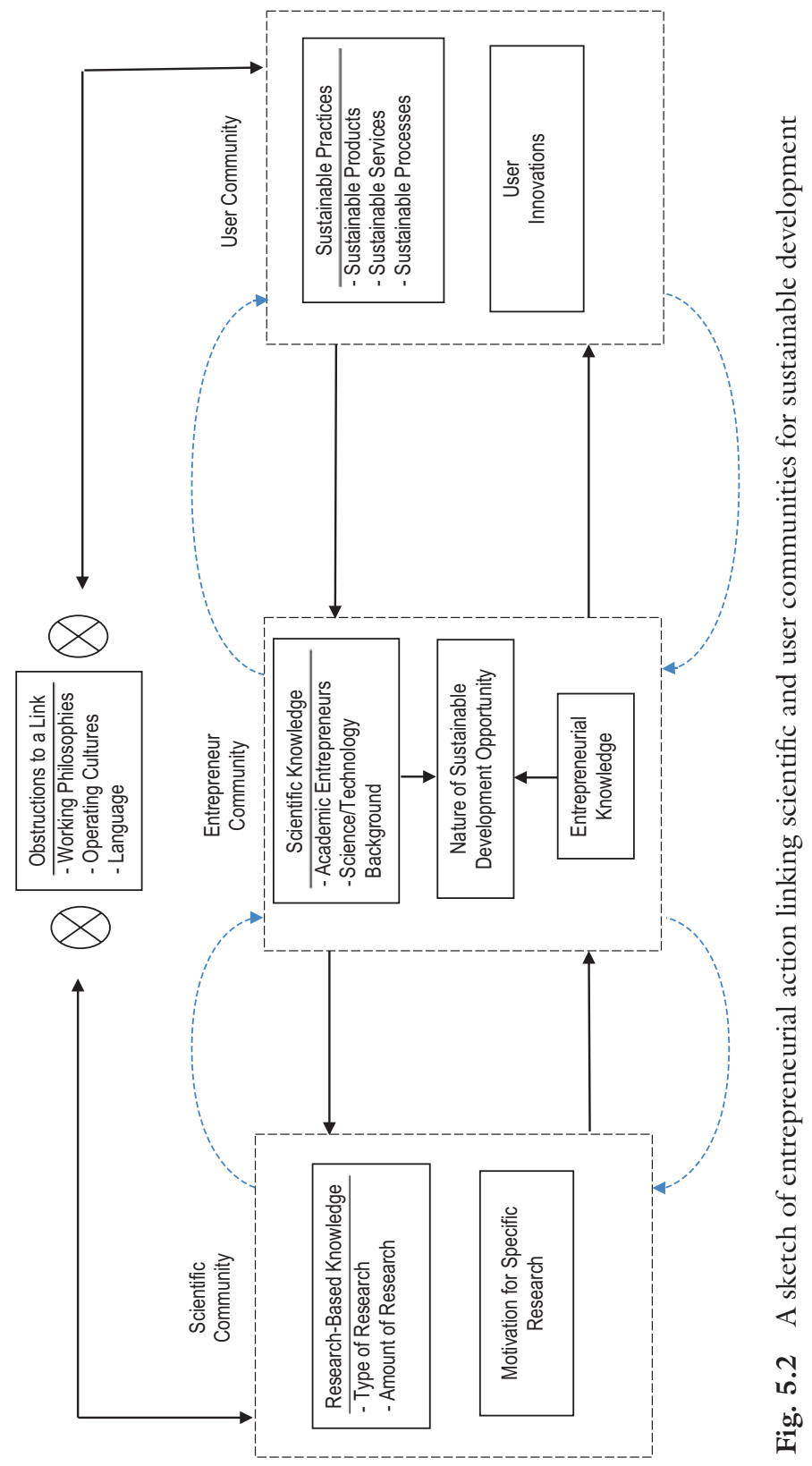


life support, and community in the pursuit of perceived opportunities to bring into existence future products, processes, and services for gain, where gain is broadly construed to include economic and non-economic gains to individuals, the economy, and society. We believe that by defining sustainable entrepreneurship, this chapter provides a basis for exploring where and how future research can make a contribution to the development of the field. Indeed, our approach to defining the field of sustainable entrepreneurship is more meta-theoretical than theoretical because we propose that scholars from different theoretical perspectives can form part of this scholarly community and that such diversity is important for sustainable entrepreneurship's further development.

At the individual level of analysis, there appears to be ample room for theorizing from a psychological perspective capturing both individuals' cognitions and emotions. For example, theories on structural alignment (Grégoire, Barr, \& Shepherd, 2010; Grégoire \& Shepherd, 2012) and prototypes (Baron \& Ensley, 2006) have been used to describe the cognitive processes underlying the recognition of entrepreneurial opportunity based on entrepreneurs' prior entrepreneurial knowledge, and they might also be helpful in explaining the identification of sustainable opportunities based on knowledge of a threat to the natural or communal environment as a starting point for (sustainable) entrepreneurial action. For example, basic needs theory as a theory of intrinsic motivation (Ryan \& Deci, 2000) or the theory on prosocial behavior (Penner, Dovidio, Piliavin, \& Schroeder, 2005) might help explain why some individuals engage in sustainable entrepreneurship and others do not. Recent work has also advocated an identity perspective to understand individuals' engagement in social (Wry \& York, 2015) and environmental (York, Hargrave, \& Pacheco, 2016) entrepreneurship. Further, Shepherd, Kuskova, and Patzelt (2009) published a psychometric scale that measures individuals' sustainability values; the "pro-environmental value" sub-scale has recently been used to explore why some entrepreneurs are more likely to exploit environmentally harmful opportunities than others (Shepherd, Patzelt, \& Baron, 2013). Importantly, our discussion also offers a "reverse perspective" putting the outcome of sustainable entrepreneurial action first - to what extent do advancements toward sustainability (e.g., success in environmental-protection projects) impact individuals' subsequent motivation and/or knowledge to (continue to) act as sustainable entrepreneurs. There is more research 
required on the reverse perspective of entrepreneurship and sustainable development. With the individual as the level of analysis, we believe future research can make important contributions for both scholarship and the practice of sustainable development.

Second, we focused on the role of entrepreneurial actions in linking different communities in co-creating and refining a potential sustainable development opportunity. Such a community-level perspective involves - but ultimately goes beyond - the individual, suggesting that theories from, for example, sociology and economics can be informative. For instance, sociologists have a long tradition of studying the evolution of scientific communities (e.g., Collins, 1983; Shapin, 1995), and they have also studied entrepreneurial communities (e.g., Portes, 1995) and the sociological implications of new technologies (e.g., Pinch \& Bijker, 1984). Similarly, scientific communities (e.g., Dasgupta \& David, 1987; Partha \& David, 1994), entrepreneurial communities (e.g., Lenzi, 1996; MacKenzie, 1992), and user communities (e.g., Lakhani \& Von Hippel, 2003; Mazzoleni \& Nelson, 2007 ) have been the focus of studies by economists. Further, recent studies (Pacheco, York, \& Hargrave, 2014; York et al., 2016) have illustrated how the complex interactions between different communities ("fields") over time led to the emergence of an environmentally friendly sector (wind energy), suggesting that reciprocal interactions between different communities shape the development of sustainable entrepreneurship and its impact on economic and environmental development. Scholars can build on this work to study the concepts and relationships offered in our earlier discussion.

In conclusion, sustainability and sustainable development are among the most important topics of our time. Sustainable entrepreneurship can make important contributions to help preserve the natural and communal environment in which we live. However, research on sustainable entrepreneurship is still in its infancy. There are many interesting and important research questions both within and outside the topics we outlined in this chapter, including research using different theoretical lenses, levels of analysis, and/or research methods. Therefore, we hope that readers find our research suggestions interesting, but we also expect that readers, based on their different backgrounds and interests, will come up with different research questions and approaches that will advance the field of sustainable development. 


\section{REFERENCES}

Baron, R. A., \& Ensley, M. D. (2006). Opportunity recognition as the detection of meaningful patterns: Evidence from comparisons of novice and experienced entrepreneurs. Management Science, 52(9), 1331-1344.

Batson, C. D. (1991). The altruism question: Toward a social-psychological answer. Hillsdale, NJ: Erlbaum.

Beck, A. T., \& Clark, D. A. (1997). An information processing model of anxiety: Automatic and strategic processes. Behaviour Research and Therapy, 35(1), $49-58$.

Board Sustainable Development. (1999). Our common journey: A transition toward sustainability. Washington, DC: National Academy.

Borer, M. I. (2006). Important place and their public faces: Understanding Fenway Park as a public symbol. The Journal of Popular Culture, 39(2), 205-224.

Bruckmeier, K. (2005). Interdisciplinary conflict analysis and conflict mitigation in local resource management. AMBIO: A Journal of the Human Environment, $34(2), 65-73$.

Bruno, A. V., McQuarrie, E. F., \& Torgrimson, C. G. (1992). The evolution of new technology ventures over 20 years: Patterns of failure, merger, and survival. Journal of Business Venturing, 7(4), 291-302.

Burton, B. K., \& Goldsby, M. (2009). Corporate social responsibility orientation, goals, and behavior a study of small business owners. Business \& Society, 48(1), 88-104.

Busenitz, L. W., West III, G. P., Shepherd, D. A., Nelson, T., Chandler, G. N., \& Zacharakis, A. (2003). Entrepreneurship research in emergence: Past trends and future directions. Journal of Management, 29(3), 285-308.

Cannella, A. A., \& Paetzold, R. L. (1994). Pfeffer's barriers to the advance of organizational science: A rejoinder. Academy of Management Review, 19(2), 331-341.

Cohen, B., \& Winn, M. I. (2007). Market imperfection, opportunity and sustainable entrepreneurship. Journal of Business Venturing, 22(1), 29-49.

Collins, H. M. (1983). The sociology of scientific knowledge: Studies of contemporary science. Annual Review of Sociology, 9, 265-285.

Conger, R. D., \& Donnellan, M. B. (2007). An interactionist perspective on the socioeconomic context of human development. Annual Review of Psychology, $58,175-199$.

Dasgupta, P., \& David, P. A. (1987). Information disclosure and the economics of science and technology. In G. R. Feiwel (Ed.), Arrow and the ascent of modern economic theory (pp. 519-542). London: Palgrave Macmillan.

Davis, M. H. (1996). Empathy: A social psychological approach. Madison, WI: Westview Press. 
Dean, T. J., \& McMullen, J. S. (2007). Toward a theory of sustainable entrepreneurship: Reducing environmental degradation through entrepreneurial action. Journal of Business Venturing, 22(1), 50-76.

Diener, E., Diener, M., \& Diener, C. (1995). Factors predicting the subjective well-being of nations. Journal of Personality and Social Psychology, 69(5), 851-864.

Dijker, A. J. (2001). The influence of perceived suffering and vulnerability on the experience of pity. European Journal of Social Psychology, 31(6), 659-676.

du Cros, H., Bauer, T., Lo, C., \& Rui, S. (2005). Cultural heritage assets in China as sustainable tourism products: Case studies of the Hutongs and the Huanghua section of the Great Wall. Journal of Sustainable Tourism, 13(2), 171-194.

Easterly, W. (2006). The white man's burden. Why the west's efforts to aid the rest have done so much ill and so little good. New York: Penguin Press.

Eisenberg, N. (1994). Empathy: A social-psychological approach. Contemporary Psychology, 39(11), 1026-1027.

Eisenberg, N. (2000). Emotion, regulation, and moral development. Annual Review of Psychology, 51(1), 665-697.

Eisenberg, N., Wentzel, M., \& Harris, J. D. (1998). The role of emotionality and regulation in empathy-related responding. School Psychology Review, 27(4), 506-521.

Etzioni, A. (1996). The golden rule. New York: Basic Books.

Ewing, S. A., Grayson, R. B., \& Argent, R. M. (2000). Science, citizens, and catchments: Decision support for catchment planning in Australia. Society \& Natural Resources, 13(5), 443-459.

Feyerabend, P. (1980). Against method. London: Verso.

Foo, M.-D., Uy, M. A., \& Baron, R. A. (2009). How do feelings influence effort? An empirical study of entrepreneurs' affect and venture effort. Journal of Applied Psychology, 94(4), 1086.

Forste, R., \& Heaton, T. B. (2004). The divorce generation: Well-being, family attitudes, and socioeconomic consequences of marital disruption. Journal of Divorce and Remarriage, 41(1-2), 95-114.

Freeman, R. E. A. (1994). A stakeholder theory of the modern corporation. In T. L. Beauchamp \& N. E. Bowie (Eds.), Ethical theory and business (pp. 66-76). Englewood Cliffs, NJ: Prentice-Hall.

Gallo, L. C., \& Matthews, K. A. (2003). Understanding the association between socioeconomic status and physical health: Do negative emotions play a role? Psychological Bulletin, 129(1), 10-51.

Gould, S. J. (1981). The mismeasure of man. New York: Norton \& Company.

Grégoire, D. A., Barr, P. S., \& Shepherd, D. A. (2010). Cognitive processes of opportunity recognition: The role of structural alignment. Organization Science, 21(2), 413-431. 
Grégoire, D. A., \& Shepherd, D. A. (2012). Technology-market combinations and the identification of entrepreneurial opportunities: An investigation of the opportunity-individual nexus. Academy of Management Journal, 55(4), $753-785$.

Hanson, M., \& Chen, E. (2007). Socioeconomic status and health behaviors in adolescence: A review of the literature. Journal of Behavioral Medicine, 30(3), 263-285.

Havens, K. E., \& Aumen, N. G. (2000). Hypothesis-driven experimental research is necessary for natural resource management. Environmental Management, $25(1), 1-7$.

Hoffman, M. L. (1982). Development of prosocial motivation: Empathy and guilt. The Development of Prosocial Behavior, 281-313.

IPCC. (2007). Intergovernmental panel on climate change, IPCC Annual Report.

Jacobsson, S., \& Bergek, A. (2004). Transforming the energy sector: The evolution of technological systems in renewable energy technology. Industrial and Corporate Change, 13(5), 815-849.

Jobert, A., Laborgne, P., \& Mimler, S. (2007). Local acceptance of wind energy: Factors of success identified in French and German case studies. Energy policy, 35(5), 2751-2760.

Kasperson, R. E. (2006). Rerouting the stakeholder express. Global Environmental Change, 16(4), 320-322.

Knight, F. H. (1921). Risk, uncertainty and profit. New York: Hart, Schaffner and Marx.

Knowles, S., \& Owen, P. D. (1995). Health capital and cross-country variation in income per capita in the Mankiw-Romer-Weil model. Economics Letters, 48(1), 99-106.

Kuhn, T. S. (1974). The structure of scientific revolutions (2nd ed.). Chicago: International Encyclopedia of Unified Science, University of Chicago.

Lakhani, K. R., \& Von Hippel, E. (2003). How open source software works: "Free" user-to-user assistance. Research Policy, 32(6), 923-943.

Leiserowitz, A. A., Kates, R. W., \& Parris, T. M. (2006). Sustainability values, attitudes, and behaviors: A review of multinational and global trends. Annual Reviews of Environmental Resources, 31, 413-444.

Lemos, M. C., \& Morehouse, B. J. (2005). The co-production of science and policy in integrated climate assessments. Global Environmental Change, 15(1), 57-68.

Lenzi, R. C. (1996). The entrepreneurial community approach to community economic development. Economic Development Review, 14(2), 16-20.

Lewis, J. I., \& Wiser, R. H. (2007). Fostering a renewable energy technology industry: An international comparison of wind industry policy support mechanisms. Energy Policy, 35(3), 1844-1857.

MacKenzie, L. R. (1992). Fostering entrepreneurship as a rural economic development strategy. Economic Development Review, 10(4), 38-44. 
Mallett, A. (2007). Social acceptance of renewable energy innovations: The role of technology cooperation in urban Mexico. Energy Policy, 35(5), 2790-2798.

Margalit, M., \& Halbertal, M. (2004). Liberalism and the right to culture. Social Research, 71(3), 529-548.

Mathews, A., \& MacLeod, C. (1994). Cognitive approaches to emotion and emotional disorders. Annual Review of Psychology, 45, 25-50.

Mazzoleni, R., \& Nelson, R. R. (2007). Public research institutions and economic catch-up. Research Policy, 36(10), 1512-1528.

McDermott, R., O’Dea, K., Rowley, K., Knight, S., \& Burgess, P. (1998). Beneficial impact of the homeland movement on health outcomes in central Australian Aborigines. Australian and New Zealand Journal of Public Health, 22, 653-658.

McMullen, J. S., \& Shepherd, D. A. (2006). Entrepreneurial action and the role of uncertainty in the theory of the entrepreneur. Academy of Management Review, 31(1), 132-152.

McWilliams, A., \& Siegel, D. (2001). Corporate social responsibility: A theory of the firm perspective. Academy of Management Review, 26(1), 117-127.

Meijnders, A. L., Midden, C. J., \& Wilke, H. A. (2001). Role of negative emotion in communication about $\mathrm{CO}_{2}$ risks. Risk Analysis, 21(5), 955-955.

Miller, J. (2001). Family and community integrity. Journal of Sociology and Social Welfare, 28, 23-44.

Monforti, F., Bellasio, R., Bianconi, R., Clai, G., \& Zanini, G. (2004). An evaluation of particle deposition fluxes to cultural heritage sites in Florence, Italy. Science of the Total Environment, 334, 61-72.

Montgomery, M. A., \& Elimelech, M. (2007). Water and sanitation in developing countries: Including health in the equation. Environmental Science and Technology, 4l(1), 17-24.

Muehlebach, A. (2001). Making place at the United Nations: Indigenous cultural politics at the U.N. working group on indigenous populations. Cultural Anthropology, 16(3), 415-448.

Narayan, D., \& Petesch, P. (2002). Voices of the poor. Oxford: Oxford University Press.

National Research Council. (1999). Our common journal. A transition toward sustainability. Washington, DC: National Academy Press.

Oakes, J. M., \& Rossi, P. H. (2003). The measurement of SES in health research: Current practice and steps toward a new approach. Social Science \& Medicine, $56(4), 169-184$.

Ogbor, J. O. (2000). Mythicizing and reification in entrepreneurial discourse: Ideology-critique of entrepreneurial studies. Journal of Management Studies, $37(5), 605-635$.

O'Neill Jr., D. G., Hershauer, J. C., \& Golden, J. S. (2009). The cultural context of sustainability entrepreneurship. Greener Management International, 55, $33-46$. 
Ornetzeder, M., \& Rohracher, H. (2006). User-led innovations and participation processes: Lessons from sustainable energy technologies. Energy Policy, 34(2), $138-150$.

Pacheco, D. F., York, J. G., \& Hargrave, T. (2014). The co-evolution of industries, social movements, and institutions: The case of wind power. Academy of Management Proceedings, 2011(1), 1-6.

Padua, M. G. (2007). Designing an identity: The synthesis of a post-traditional landscape vocabulary in Hong Kong. Landscape Research, 32(2), 225-240.

Parkhe, A. (1992). U.S. national security export controls: Implications for global competitiveness of U.S. high-tech firms. Strategic Management Journal, 13(1), $47-66$.

Parris, T. M., \& Kates, R. W. (2003). Characterizing and measuring sustainable development. Annual Review of Environment and Resources, 28, 559-586.

Partha, D., \& David, P. A. (1994). Toward a new economics of science. Research Policy, 23(5), 487-521.

Pastakia, A. (1998). Grassroots ecopreneurs: Change agents for a sustainable society. Journal of Organizational Change Management, 11(2), 157-173.

Penner, L. A., Dovidio, J. F., Piliavin, J. A., \& Schroeder, D. A. (2005). Prosocial behavior: Multilevel perspectives. Annual Review of Psychology, 56, 365-392.

Peredo, A. M., \& Chrisman, J. J. (2006). Toward a theory of community-based enterprise. Academy of Management Review, 31(2), 309-328.

Pfeffer, J. (1993). Barriers to the advance of organizational science: Paradigm development as a dependent variable. Academy of Management Review, 18(4), 599-620.

Pinch, T. J., \& Bijker, W. E. (1984). The social construction of facts and artefacts: Or how the sociology of science and the sociology of technology might benefit each other. Social Studies of Science, 14(3), 399-441.

Porter, G. (1995). Environmental security as a national security issue. Current History, 94(592), 218-222.

Portes, A. (1995). The economic sociology of immigration: Essays on networks, ethnicity, and entrepreneurship. New York: Russell Sage Foundation.

Pretty, J., Hine, R., \& Peacock, J. (2006). Green exercise: The benefits of activities in green places. Biologist, 53(3), 143-148.

Ribot, J. C. (2006). Choose democracy: Environmentalists' socio-political responsibility. Global Environmental Change, 16, 115-119.

Roberts, E. B. (1991). Entrepreneurs in high technology: Lessons from MIT and beyond. Oxford: Oxford University Press.

Rogers, E. M. (1995). Diffusion of innovations: Modifications of a model for telecommunications. In M. W. Stoetzer \& A. Mahler (Eds.), Die diffusion von innovationen in der telekommunikation (pp. 25-38). Berlin and Heidelberg: Springer.

Roux, D. J., Rogers, K. H., Biggs, H., Ashton, P. J., \& Sergeant, A. (2006). Bridging the science-management divide: Moving from unidirectional knowl- 
edge transfer to knowledge interfacing and sharing. Ecology and Society, $11(1)$, $4-23$.

Ryan, R. M., \& Deci, E. L. (2000). The darker and brighter sides of human existence: Basic psychological needs as a unifying concept. Psychological Inquiry, 11(4), 319-338.

Sala, E., \& Knowlton, N. (2006). Global marine biodiversity trends. Annual Review of Environment and Resources, 31, 93-122.

Schaper, M. (2005). Making ecopreneurs: Developing sustainable entrepreneurship (pp. 61-70). Burlington, VT: Ashgate.

Schröter, D., Cramer, W., Leemans, R., Prentice, I. C., Araújo, M. B., Arnell, N. W., et al. (2005). Ecosystem service supply and vulnerability to global change in Europe. Science, 310, 1333-1337.

Seelos, C., \& Mair, J. (2005). Social entrepreneurship: Creating new business models to serve the poor. Business Horizons, 48(3), 241-246.

Shane, S. (2000). Prior knowledge and the discovery of entrepreneurial opportunities. Organization Science, 11(4), 448-469.

Shane, S. A. (2004). Academic entrepreneurship: University spinoffs and wealth creation. Cheltenham, UK: Edward Elgar Publishing.

Shapin, S. (1995). Here and everywhere-Sociology of scientific knowledge. Annual Review of Sociology, 21, 289-321.

Shepherd, D. A., Kuskova, V., \& Patzelt, H. (2009). Measuring the values that underlie sustainable development: The development of a valid scale. Journal of Economic Psychology, 30, 246-256.

Shepherd, D. A., \& Patzelt, H. (2011). The new field of sustainable entrepreneurship: Studying entrepreneurial action linking "what is to be sustained" with "what is to be developed". Entrepreneurship Theory and Practice, 35(1), 137-163.

Shepherd, D. A., Patzelt, H., \& Baron, R. A. (2013). "I care about nature, but ...": Disengaging values in assessing opportunities that cause harm. Academy of Management Journal, 56(6), 1251-1273.

Slaper, H., Velders, G. J. M., Daniel, J. S., de Gruijl, F. R., \& van der Leun, J. C. (1996). Estimates of ozone depletion and skin cancer incidence to examine the Vienna Convention achievements. Nature, 384(6606), 256-258.

Sonune, A., \& Ghate, R. (2004). Developments in wastewater treatment methods. Desalination, 167, 55-63.

Spicer, P. (2001). Culture and the restoration of self among former American Indian drinkers. Social Science and Medicine, 53(2), 227-240.

Steinbruner, J. D. (1978). National security and the concept of strategic stability. The Journal of Conflict Resolution, 22(3), 411-428.

Summer, C. E., Bettis, R., Duhaime, I., Grant, J. H., Hambrick, D. C., Snow, C. C., et al. (1990). Doctoral education in the field of business policy and strategy. Journal of Management, 16(2), 361-391. 
Swanson, T. N. (1996). The economics of environmental degradation. Cheltenham, UK: Edward Elgar.

Thompson, J., \& Scoones, I. (1994). Challenging the populist perspective: Rural people's knowledge, agricultural research, and extension practice. Agriculture and Human Values, 11(2-3), 58-76.

Tuinstra, W., Hordijk, L., \& Kroeze, C. (2006). Moving boundaries in transboundary air pollution co-production of science and policy under the convention on long range transboundary air pollution. Global Environmental Change, 16(4), 349-363.

Twenge, J. M., \& Campbell, W. K. (2002). Self-esteem and socioeconomic status: A meta-analytic review. Personality \& Social Psychology Review, 6, 59-71.

United Nations. (2004). UNEP 2004 Annual Report.

Van Kerkhoof, L., \& Lebel, L. (2006). Linking knowledge and action for sustainable development. Annual Review of Environmental Resources, 31, 445-477.

Vemuri, A. W., \& Costanza, R. (2006). The role of human, social, built and natural capital in explaining life satisfaction at the country level: Toward a national well-being Index. Ecological Economics, 58(1), 119-133.

Venkataraman, S. (1997). The distinctive domain of entrepreneurship research. In J. Katz (Ed.), Advances in entrepreneurship, firm emergence, and growth (pp. 119-138). Greenwich: JAI Press.

von Hippel, E. (1988). The sources of innovation. New York: Oxford University Press.

Wei, M., Shaffer, P. A., Young, S. K., \& Zakalik, R. A. (2005). Adult attachment, shame, depression, and loneliness: The mediation role of basic psychological needs satisfaction. Journal of Counseling Psychology, 52(4), 591-601.

Welp, M., de la Vega-Leinert, A., Stoll-Kleemann, S., \& Jaeger, C. C. (2006). Science-based stakeholder dialogues: Theories and tools. Global Environmental Change, 16(2), 170-181.

Wheeler, D., McKague, K., Thomson, J., Davies, R., Medalye, J., \& Prada, M. (2005). Creating sustainable local enterprise networks. Sloan Management Review, 47(1), 33-40.

Wood, J. V., Saltzberg, J. A., \& Goldsamt, L. A. (1990). Does affect induce selffocused attention? Journal of Personality and Social psychology, 58(5), 899-908.

Wry, T., \& York, J. G. (2015). An identity based approach to social enterprise. Academy of Management Review. doi:10.5465/amr.2013.0506.

York, J. G., Hargrave, T. J., \& Pacheco, D. F. (2016). Converging winds: Logic hybridization in the Colorado wind energy field. Academy of Management Journal, 59(2), 579-610.

Yunus, M. (2005). Grameen Bank's struggling (beggar) members programme. Retrieved from http://www.grameeninfo.org/index.php

Zahra, S. A., Gedajlovic, E., Neubaum, D. O., \& Shulman, J. M. (2009). A typology of social entrepreneurs: Motives, search processes and ethical challenges. Journal of Business Venturing, 24(5), 519-532. 
Zedler, J. B., \& Kercher, S. (2005). Wetland resources: Status, trends, ecosystem services, and restorability. Annual Review of Environment and Resources, 30, 39-74.

Zucker, L. G., Darby, M. R., \& Brewer, M. B. (1998). Intellectual human capital and the birth of US biotechnology enterprises. American Economics Review, $88(1), 290-306$.

Open Access This chapter is distributed under the terms of the Creative Commons Attribution 4.0 International License (http://creativecommons.org/licenses/by/4.0/), which permits use, duplication, adaptation, distribution and reproduction in any medium or format, as long as you give appropriate credit to the original author(s) and the source, provide a link to the Creative Commons license and indicate if changes were made.

The images or other third party material in this chapter are included in the work's Creative Commons license, unless indicated otherwise in the credit line; if such material is not included in the work's Creative Commons license and the respective action is not permitted by statutory regulation, users will need to obtain permission from the license holder to duplicate, adapt or reproduce the material.

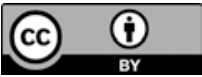

